\title{
Uma avaliação da gestão participativa do conselho municipal de educação de Mossoró- $\mathbf{R N}$
}

An evaluation of the participatory management of the municipal council for education of Mossoró-RN

Una evaluación de la gestión participativa del concejo educacional del municipio de Mossoró-RN

Recebido: 18/06/2021 | Revisado: 24/06/2021 | Aceito: 25/06/2021 | Publicado: 12/07/2021

Everkley Magno Freire Tavares

https://orcid.org/0000-0002-3277-3994

Serviço Nacional de Aprendizagem Industrial, Brasil everkleymagno@gmail.com

\begin{abstract}
Resumo
Esta investigação teve como objetivo avaliar a efetividade da gestão participativa do Conselho Municipal de Educação CME de Mossoró sob a ótica dos atores relevantes e insere-se num conjunto de pesquisas que são realizadas atualmente no Brasil sobre o impacto dos conselhos gestores de políticas públicas educacionais. A pesquisa de caráter quantiqualitativa utilizou um questionário eletrônico formulado no Google Forms, tendo como amostra 83,3\% de respondentes do universo de 12 conselheiros da gestão 2016/2018 do CME de Mossoró-RN. Procedemos também com uma entrevista estruturada com 4 conselheiros, além de levantamento documental e participação em reuniões, aspectos fundamentais para uma análise de SWOT do Conselho, objetivando também apontar prescrições sobre os pontos focais de oportunidades e melhorias para a gestão participativa. Tomando por base os índices construídos e os relatos dos entrevistados, consideramos que o nível geral de desempenho do conselho é "excelente" e "razoável" como espaço paritário, consultivo e deliberativo das políticas públicas e demandas educacionais do município.
\end{abstract}

Palavras-chave: Gestão participativa; Conselho municipal de educação; Políticas públicas.

\begin{abstract}
This investigation aimed to evaluate the effectiveness of the participatory management of the Conselho Municipal de Educação - CME (Municipal Council for Education) of Mossoró from the perspective of relevant social actors, it is part of a set of research currently being carried out in Brazil on the impact of management councils on educational public policy. The quanti-qualitative research used an electronic questionnaire formulated in Google Forms, with a sample of 83.3\% of respondents from the universe of 12 councilors of the 2016/2018 management of the CME of Mossoró-RN. We also proceeded with a structured interview with 4 councilors, in addition to a documentary survey and participation in meetings, fundamental aspects for a SWOT analysis of the Council, aiming also to point out prescriptions on the focal points of opportunities and improvements for participatory management. Based on the constructed indexes and the interviewees' reports, we consider that the council's general level of performance is "excellent" and "reasonable" as a joint, consultative, and deliberative space for the municipality's public policies and educational demands.
\end{abstract}

Keywords: Participatory management; Municipal council for education; Public policy.

\section{Resumen}

La presente exploración tuvo como objetivo evaluar la efectividad de la gestión interactiva del Concejo Municipal de Educación - CME de Mossoró bajo la óptica de los actores relevantes y se inserta en un conjunto de pesquisas que son realizadas actualmente en Brasil al respecto del impacto de los concejos gestores de políticas públicas educacionales. La investigación cuanti-cualitativa utilizó un cuestionario electrónico formulado en el Google Forms, teniendo como amuestra 83,3\% de respondientes del universo de 12 consejeros de la gestión 2016/2018 del CME de Mossoró-RN. Procedemos también con una entrevista constituida por 4 consejeros, además de averiguación documental y participación en reuniones, aspectos fundamentales para un análisis de SWOT del Concejo, objetivando todavía apuntar prescripciones al respecto a los puntos focales de oportunidades y mejorías para la gestión participativa. Basándose a los índices construidos y a los relatos de los entrevistados, consideramos que el nivel general de desempeño del concejo es "excelente" y "razonable" como espacio paritario, consultivo y deliberativo de las políticas públicas y demandas educacionales del municipio.

Palabras clave: Gestión participativa; Concejo municipal de educación; Políticas públicas.

\section{Introdução}

As avaliações fazem parte do ciclo de gestão das políticas públicas e são indicadores estratégicos para a atuação dos stakeholders nos Conselhos Municipais de Educação - CMEs ao possibilitarem aos gestores públicos e aos atores relevantes, 
diagnósticos ex-ante, de processo e ex-post das ações programáticas implementadas pelos entes públicos. Com a Constituição Federal de 1988 os conselhos gestores foram constituídos como instâncias democráticas para a gestão de políticas públicas no Brasil.

Com os conselhos gestores as políticas públicas passam a serem discutidas, decididas e deliberadas nos espaços decisórios da coisa pública, e, sobretudo, garantindo informações sobre o processo de implementação/resultados alcançados pelas políticas.

As crescentes reivindicações da sociedade civil pela efetividade das políticas públicas e a efetivação do direito à educação com qualidade e equidade através do planejamento estratégico público no Brasil têm chamado a atenção para uma aplicação mais razoável dos recursos públicos, contando com transparência e responsabilidade em respeito a supremacia do interesse coletivo nas decisões tomadas frente as demandas educacionais existentes em cada território.

Dessa forma, o percurso avaliativo da gestão dos conselhos de políticas públicas conduz as prescrições necessárias ao feedback para os atores relevantes. As avaliações prescritivas apontam oportunidades de melhoria e conduzem ao processo corretivo das políticas públicas executadas e implementadas de forma participativa a cada novo ciclo. Sob esta perspectiva as avaliações de eficácia, eficiência, relevância e efetividade dos Conselhos de políticas públicas são necessárias para as prescrições, contemplando o exame da definição de metas diante das demandas ou problemas públicos locais, a definição de prioridades para a agenda pública, a alocação adequada de recursos e esforços para o alcance das metas, a mensuração de efeitos do processo de implementação e os resultados alcançados.

É preciso ainda destacar o fato de que há uma íntima ligação entre a atuação participativa dos Conselhos Municipais e a efetividade das políticas públicas. A atuação dos Conselhos Gestores de Políticas Públicas é definida pela proposta e execução de gestão participativa. A gestão participativa é aquela que viabiliza a intervenção de atores relevantes nos processos de tomada de discussão, decisão, deliberação e controle social das políticas públicas (Tavares, 2011).

A gestão participativa no campo educacional é um processo de democratização das etapas de discussão, decisão e deliberação presentes no processo decisório sobre as agendas públicas, implementação das políticas e tratamento das demandas educacionais, envolvendo a participação de diferentes agentes da comunidade escolar, do poder público e da sociedade através da constituição de espaços formais e não formais de participação sociopolítica, tais como, os conselhos escolares, reuniões setoriais nas escolas/comunidades e na constituição dos conselhos municipais de educação (Dagnino, 2002., Gohn, 2001).

A gestão participativa gera oportunidades políticas e estratégicas para a democratização da gestão pública brasileira, na medida em que politiza o processo decisório em todo o ciclo de vida das políticas públicas educacionais, desde a elaboração, passando pela implementação e a avaliação de resultados, conferindo em muitas experiências uma certa possibilidade de efetividade/impacto dos programas, políticas e projetos públicos (Cohen \& Franco, 1993., Soares \& Cassia-Bava, 1998., Rico, 2007).

Mossoró é a segunda maior cidade do estado do Rio Grande do Norte com uma população estimada em 2017 de 295.619 habitantes, também se destaca por estar entre os cinco municípios com maior IDH do RN e com um IDEB/2015 de 5,2 que na trajetória histórica de 2005 a 2015 vem crescendo e apresentando indicadores significativos de desenvolvimento da educação municipal. Nesse ponto, a pesquisa, sobre a atuação do CME que em 2018 completou 21 anos se faz necessária para comparar as contribuições do conselho na efetividade das políticas públicas educacionais municipais e fazer prescrições para o seu ótimo desempenho.

O estudo aqui apresentado está relacionado a avaliação participativa através uma avaliação que pretende responder as seguintes problemáticas: Qual o nível de desempenho da gestão participativa do CME e as suas contribuições para a efetividade das políticas públicas educacionais do município? O percurso analítico teve como objetivo geral: Conhecer a proposta de gestão participativa do Conselho Municipal de Educação - CME de Mossoró-RN. A investigação buscou atingir os seguintes objetivos 
específicos: Discutir a constituição dos Conselhos Municipais de Educação como instâncias participativas, consultivas e deliberativas das políticas públicas educacionais. Caracterizar o perfil, a constituição e a atuação do Conselho Municipal de Educação - CME de Mossoró-RN. Realizar uma avaliação prescritiva para o CME através da análise estratégica das oportunidades, ameaças, forças e fraquezas da atuação do CME, em conexão com a efetividade das políticas públicas educacionais.

\section{Metodologia}

As pesquisas de avaliação da atuação dos conselhos gestores de políticas públicas são necessárias para conhecer as propostas de gestão participativa em curso no campo educacional brasileiro, na medida em que pontua e confronta realidades nacionais e locais mediante o exame dos processos participativos intrínsecos a atuação dos conselhos e a efetividade das políticas públicas, principalmente nos contextos de ataques a democracia participativa e ao controle social das políticas públicas.

Como estratégia metodológica, avaliamos a atuação do CME de Mossoró-RN na gestão atual, identificando permanências e rupturas do processo decisório das políticas públicas educacionais. Também foi aplicada a análise de matriz SWOT para monitorar os fatores externos e internos que influenciam o CME na sua gestão participativa, observando estrategicamente as oportunidades, ameaças, forças e fraquezas, com o intuito de otimização da proposta de gestão e fazer prescrições.

Para o alcance das dimensões supracitadas, recorreu-se a aplicação de métodos quantitativos e qualitativos, entre eles: levantamento de documentos do conselho (Lei de constituição, Regimento Interno, Planos de Ação e Atas), participação em reuniões para o conhecimento da dinâmica de funcionamento e o perfil sócio-político dos conselheiros. Aplicação de um questionário eletrônico formulado no Google Forms, tendo como amostra 83,3\% de respondentes do universo de 12 conselheiros da atual gestão do CME de Mossoró-RN, para otimizar as respostas foi criando um grupo no WhatsApp com os conselheiros após o consentimento prévio dos mesmos e como recurso qualitativo, utilizamos a entrevista estruturada com 4 conselheiros, sendo dois representantes da sociedade civil e dois do poder público local (Rosa \& Arnardi, 2008., Oliveira, 2007).

A escolha dos entrevistados foi pautada por critérios de representatividade diante do quadro paritário de constituição do conselho. Os entrevistados assinaram um Termo de Consentimento Livre e Esclarecido - TCLE, antes da realização da entrevista, sendo explicada a importância da pesquisa acerca da Gestão Participativa Conselho Municipal de Educação e efetividade das políticas educacionais. Realizamos o emprego do questionário e das entrevistas para comparar as percepções e empreender analises mais aprofundadas da atuação dos conselheiros e do CME, mediante o tratamento dos resultados quantitativos e qualitativos.

A aplicação da matriz SWOT possibilitou monitorar os fatores externos e internos que influenciam o Conselho na realização de suas funções, sendo observados os fatores relevantes para um diagnóstico sobre a situação do Conselho Municipal de Educação de Mossoró, verificando suas oportunidades, ameaças, forças e fraquezas.

A análise de SWOT é uma ferramenta que monitora o ambiente interno e externo da instituição. A análise realizada pelo ambiente externo é feita através do diagnóstico de dois parâmetros que são as oportunidades e ameaças. Então uma organização deve identificar possíveis mudanças que podem acontecer no seu ambiente externo, verificando algumas tendências, podendo ajudála a conquistar uma oportunidade e diferencial ou então de identificar uma possível ameaça a sua organização, através de fatores exógenos. Já a análise realizada pelo ambiente interno é feita através de dois parâmetros que são as forças e as fraquezas. Nas forças são verificadas as características mais fortes que diferenciam das outras organizações, sendo o diferencial que o conselho vai possuir perante os outros. Nas fraquezas são verificadas as características que atrapalham o andamento dos processos dentro da organização, dessa forma prejudicando o andamento da gestão participativa do CME.

Segundo Tavares (2010) a análise SWOT, também conhecida como FOFA (em sua tradução) é uma técnica que faz a relação entre o ambiente interno e externo da organização, verificando alguns fatores. No ambiente externo são verificadas as oportunidades que podem ser usadas para melhorar o desempenho do conselho e as ameaças que podem atrapalhar o desempenho 
do mesmo. No ambiente interno são verificadas as forças e as fraquezas. As forças correspondem aos recursos internos que trazem benefícios e vantagens competitivas para a organização. As fraquezas são aspectos que causam problemas internos na organização, dessa forma obtendo um desempenho fraco. Essa técnica foi desenvolvida, em muitos casos, para guiar o desenvolvimento organizacional e a efetividade das políticas educacionais.

\section{Resultados e Discussões}

Os conselhos municipais de educação fazem parte das inovações institucionais no campo da gestão pública dentro do contexto da democratização e da descentralização política e administrativa no Brasil, como bem aponta Batista (2009, p. 14): ... a história dos conselhos de educação situa-se no campo da gestão pública e encontra o fio condutor nos processos de democratização e descentralização, cujo eixo central é o poder. Os conselhos gestores constituem - se em espaços de inovação e abertura democráticas na gestão pública brasileira (Tavares, 2011., Valle, 2011)

A organização desses novos padrões de gestão concorre para sedimentar uma nova cultura política ao romper e se manter resistente a tradição autoritária e elitista que há muito influencia a administração pública no Brasil (Tavares, 2011). Daí muitas experiências de avaliação da atuação dos conselhos municipais de educação no Brasil têm caminhado no sentido de apontar subsídios para a reformulação de políticas e a sua adequação às necessidades da população, considerando os recursos públicos disponíveis e as prioridades das agendas públicas. Também se tem falado da avaliação da gestão participativa dos conselhos gestores como uma estratégia de busca da excelência no exercício da gestão pública, potencializando a eficácia, a eficiência, a relevância e a efetividade de políticas públicas como elementos dinamizadores do impacto social, por exemplo, os resultados de qualidade e equidade da educação municipal.

A abertura para novos agentes organizacionais e a constituição de novos arranjos políticos para a participação cidadã têm mostrado serem condições fundamentais para que as demandas e reivindicações da população ganhem visibilidade e legitimidade. A partir dessa prática, a gestão pública abre espaço para a participação popular na gestão local ao compartilhar o poder decisórios sobre as questões públicas.

Nessa perspectiva, a proposta de uma educação com qualidade e equidade implica, portanto, na indução da democratização da vida social através da mobilização da sociedade para a gestão participativa das políticas públicas educacionais, na democratização do poder local através de estratégias e canais de participação social, do reforço a ampliação das organizações sociais, promoção de parcerias e existência de sistemas de informação abertos, através dos quais a população tenha em tempo real maiores informações sobre os recursos disponíveis, os planos de ação dos diferentes setores da administração pública e os gastos públicos setoriais (Gohn, 2001).

A discussão da gestão participativa carece de investigações que aprofundem o olhar sobre a dimensão política das ações dos atores relevantes e suas organizações envolvidas no processo de gestão das políticas públicas através de conselhos gestores de forma democrática e pluralista. Os temas da democracia e da participação constituem-se em princípios fundamentais para a gestão pública no Brasil (Jacobi \& Pinho, 2006).

Corroborando com esse posicionamento no campo do sistema/rede educacional Gadotti \& Romão (1997, p.16 apud Libâneo, 2013, p.116) apontam:

Todos os segmentos da comunidade podem compreender melhor o funcionamento da escola, conhecer com mais profundidade os que nela estudam e trabalham, intensificar seu envolvimento com ela e, assim, acompanhar melhor a educação ali oferecida.

A participação é entendida como o envolvimento proativo dos cidadãos em processos de tomada de decisão e controle das 
mesmas que ultrapassam os mecanismos eleitorais, consultivos e de implementação de decisões adotadas pelo governo. Na medida em que a participação se efetiva influi na efetividade da qualidade da educação.

Os conselhos gestores se constituem como espaços participativos de interface entre o Estado e a sociedade civil, articulando atores relevantes a gestão das políticas públicas no Brasil pós-80, como bem afirma Gohn (2007, p.85):

Os conselhos gestores são novos instrumentos de expressão, representação e participação; em tese, eles são dotados de potencial transformação política. Se efetivamente representativos, poderão imprimir um novo formato às políticas sociais, pois se relaciona ao processo de formação das políticas e tomadas de decisões.

Os conselhos gestores são espaços relevantes de atuação para a participação e o controle social das políticas públicas educacionais, na medida em que se otimizam as possibilidades de discussões, decisões e deliberações sobre as demandas educacionais existentes nos municípios. Os Conselhos Educacionais são ícones da descentralização e da participação instituídos obrigatoriamente nos níveis governamentais: nacional, estaduais e municipais de gestão das políticas educacionais.

Desse modo, a constituição dos Conselhos Municipais de Educação - CME está fundamentada nos princípios da participação e descentralização instituídos pela CF/88, por exemplo, nos Artigos 204 e 206 respectivamente: II - participação da população, por meio de organizações representativas, na formulação das políticas e no controle das ações em todos os níveis e IV - Gestão democrática do ensino público, na forma da lei. (Brasil, 2004, p.121)

No campo infraconstitucional a Lei de Diretrizes e Bases da Educação Nacional - Lei 9394/1996 estabelece respectivamente no art. $3^{\circ}$, inciso VII - gestão democrática do ensino público, na forma da lei e da legislação dos sistemas de ensino (Brasil, 2006, p. 18). Art. 14. Os sistemas de ensino definirão as normas de gestão democrática do ensino público na educação básica, de acordo com as suas peculiaridades e conforme os seguintes princípios: I - participação dos profissionais da educação na elaboração do projeto pedagógico da escola. II - participação das comunidades escolar e local em conselhos escolares ou equivalentes (Brasil, 2006, p.22). Também a Lei 13.005/2014 que instituiu o Plano Nacional de Educação - PNE 2014-2024 instituiu a necessidade de uma gestão participativa e democráticas das políticas públicas educacionais no seu art. $2^{\circ}$, Inciso $V I-$ promoção do princípio da gestão democrática na educação pública (Brasil, 2014, p.42).

$\mathrm{O}$ arcabouço legal constitucional e infraconstitucional estabelece como funções essenciais dos Conselhos Municipais de Educação: a articulação dos atores relevantes do Estado e da Sociedade Civil para a gestão compartilhada das políticas públicas educacionais frente as demandas apresentadas, aprimorando a agenda pública local sobre as prioridades de mitigação e resolutividade dos problemas públicos educacionais; normatizar: elaborar o arcabouçar regulatório e as diretrizes em correspondência com os condicionantes legais nacionais e estaduais em matéria de educação; assessorar: responder através de pareceres técnicos as solicitações do poder público e de segmentos da sociedade no prazo legal, de forma consultiva informar e ser um espaço reivindicatório de informações da gestão das políticas educacionais, com o intuito de publicizar as informações para os segmentos interessados da sociedade; deliberar: capacidade de exercer de forma efetiva o poder político do qual o povo é titular e encontrar no espaço dos conselhos campo de expressão e representação do interesse público, no processo de tomada de decisão, na fiscalização e monitoramento das ações programáticas definidas previamente e em execução.

Os principais resultados acerca do perfil, da constituição e da atuação do Conselho Municipal de Educação - CME de Mossoró-RN permitem fazer prescrições para otimizar o desempenho da proposta de gestão participativa do CME e do processo decisório e deliberativo das políticas públicas educacionais no município.

O Conselho Municipal de Educação - CME foi criado pela Lei Municipal 1.110 de 03 de julho de 1997 e sua composição é delineada de forma paritária por doze conselheiros, contando com representantes da administração pública municipal e representantes da sociedade civil.

O perfil dos doze conselheiros do Conselho Municipal de Educação (CME) de Mossoró-RN, da gestão 2014 a 2016 foi 
delineado através da aplicação de um questionário on-line com perguntas que possibilitaram o esboço das características em comum entre esses membros do Conselho, seus vínculos e expertises.

Assim, com base no questionário realizado, um dado coletado que chama bastante atenção é que cerca de $88,9 \%$ dos membros são mulheres com vinculação com a questão educacional em suas trajetórias profissionais e atuações sociais. Outra predominância encontrada com a mesma porcentagem é de conselheiros com pós-graduação. Essa informação do CME de MossoróRN no período pesquisado é significativa para a definição da representatividade e participação dos atores relevantes, pois, ao revelar uma trajetória de vínculos com as questões educacionais do município e expertise para o trato do processo formal de gestão das políticas, o que em certam medida também revela uma vontade participativa, competência técnica e política dos conselheiros e, consequente eficiência na proposta de gestão participativa e atuação do CME de Mossoró-RN.

Outras informações sobre o perfil dos conselheiros respondentes corresponde a predominância de $66,7 \%$ dos membros serem servidores públicos. Pode-se fazer um adendo sobre o porquê da existência dessa expressiva porcentagem, a qual decorre da forte influência do poder Executivo Municipal no Conselho, pois o prefeito do Município nomeia os conselheiros dentre as pessoas indicadas pelas instituições elencadas, conforme previsto no artigo $4^{\circ}$ da Lei Municipal n. ${ }^{\circ} 1.110$, de 3 de julho de 1997. Então, ser servidor público aumenta a probabilidade de indicação para ser um conselheiro, por estar mais próximo da instância política que pode proporcionar essa nomeação. Contudo, não é pré-requisito como único meio de inserção no Conselho, mas um caminho facilitador. Além disso, cerca de 33,3\% são professores e por dividirem uma realidade profissional semelhante, obtiveram nas respostas em torno de 44,4\% da renda familiar entre 4-8 salários mínimos.

Em suma, os dados animadores e relevantes do perfil dos membros do CME são a respeito do predomínio dos conselheiros com pós-graduação e atuantes na área da educação, pois esses dados condicionam a uma maior chance de eficácia, eficiência e efetividade do Conselho. Posto que os conselheiros devem ter formação e consciência crítica, para entenderem o contexto em que se inserem, compreendendo assim, os processos, os gastos públicos com as demandas educacionais e as prioridades de investimento diante das metas fixadas pelos Planos Educacionais.

Todo Conselho é obrigado a ter uma lei e um regimento interno que o constitua, e o organize integralmente, uma vez que, é a partir disso que surge a democratização do processo decisório. Partindo desse pressuposto, pode-se fazer uma análise minuta da lei que rege o Conselho Municipal de Educação no Município de Mossoró, notabilizada pela LEI No 1.110/97, criada junto a gestão da Prefeita Rosalba Ciarlini Rosado ( $1^{\circ}$ de janeiro de 1997 até $1^{\circ}$ de janeiro de 2005, dois mandatos consecutivos) dispondo assim sobre tal conselho e dando outras providências.

A lei é composta por 15 artigos, em que, cada um discerne um teor sobre a constituição e atuação do mesmo. Desde início é firmado que o Conselho foi criado como órgão consultivo, ou seja, tem a capacidade de julgar os assuntos; deliberativo, junto ao caráter de decisão; e normativo, onde interpreta as normas vigentes e também tem a capacidade de criar. Sendo esse órgão vinculado à Secretaria de Educação e a jurisdição da cidade, integrando-se assim, ao sistema orçamentário de tais.

Os membros são constituídos por um processo burocrático dividido entre Representantes da Administração Pública Municipal e Representantes da sociedade civil, sendo estes, formando 12 nomeados pela prefeita (o) da atual gestão. Logicamente para ser um processo justo, são instituídos seis em cada uma das duas divisões, assim sendo: da secretaria Municipal da educação, assessoria jurídica, magistério público com atuação na educação infantil, magistério público com atuação no ensino fundamental, dirigentes da escola, técnico-pedagógico (Administração Pública). Representantes da rede filantrópica, dos direitos da criança e do adolescente, da UERN, dos conselhos das escolas municipais, do sistema estadual de ensino, da rede privada, e da câmera municipal de vereadores (cabe ao âmbito da sociedade civil).

O processo de indicação dos membros do Conselho Municipal de Educação de Mossoró-RN se dá pela indicação das instituições do poder público e da sociedade civil, com o encaminhamento de atores relevantes na qualidade de titulares e suplentes. 
O conselho de educação tem por objeto principal, melhorar a situação educacional do seu município, podendo ele se responsabilizar por várias ações. Assim como, elaborar políticas e diretrizes para o seu funcionamento eficaz, além de aplicar recursos, autorizando e fixando normas de supervisão nas escolas, desenvolvendo esforços para ter a capacidade para melhorar a qualidade e imediatamente elevar os índices da produtividade do ensino, instituída por fim a eficácia do mesmo.

O processo de escolha para o presidente do Conselho que se encontrava no artigo $7^{\circ}$ da LEI $N^{\circ} 1.110 / 97$ foi modificado pelo artigo $1^{\circ}$ da LEI $N^{\circ} 2142 / 2006$, passando a ter a seguinte redação:

O conselho municipal de educação é presidido por um presidente, eleito por seus pares, em eleição secreta, mediante a apresentação das chapas, presidente e vice-presidente, para o mandato de dois anos, permitida de uma recondução consecutiva nos mesmos cargos, nomeados pelo Chefe Executivo Municipal.

Antes dessa revogação, tal processo era considerado retrocedente já que atualmente se passa por uma democracia participativa. E com a modificação, pôde-se notar que o Presidente não é mais escolhido pelo executivo, e sim de um modo mais democrático, havendo uma participação direta das instituições indicadas e através de uma lista tríplice formada pelos segmentos e, consequente apreciação dos pares.

Isto posto, os serviços administrativos caberão ao regimento interno que irá sustar a organização das atividades e ações conselhos. Mas já adiantando que, o conselho irá se reunir uma vez por mês, e no caso do Município de Mossoró, a primeira quinta feira de todo mês. Sendo criadas três Câmaras com objetivo de tratar sobre a educação infantil e ensino fundamental, legislação e normas e sobre o seu próprio planejamento, ocorrendo de nenhum dos conselheiros pertencerem a mais de uma Câmara.

A importância da instauração de tal lei no Município de Mossoró, que antes de ter sido instalada, foi submetida pela aprovação do Prefeito (a), para assim ter entrado em vigor. A partir disso, o Conselho de Educação foi instituído por um conjunto de preceitos normativos e legais, cujo o objetivo central é se constituir como espaço participativo para a melhoria da educação do município de Mossoró-RN.

Além da importância da LEI No 1.110/97, cada conselho Municipal de Educação, inclusive o do Município de Mossoró, tem o seu regimento interno uma vez que, é pautado no mesmo, a sua organização, as competências dos devidos órgãos, o funcionamento do conselho, junto com sua estrutura, membros e sessões. Partindo disso, é possível perceber ao decorrer do documento, que o Conselho é um órgão consultivo, deliberativo e normativo, estando o mesmo vinculado à educação e a jurisdição de Mossoró.

Uma das finalidades do conselho é auxiliar no processo decisório das políticas educacionais e estabelecer normas relacionadas ao ensino. Os conselhos são instituídos em todos os níveis de governo e possibilitam um regime de cooperação entre os entes federativos.

Dessa forma, os conselhos municipais de educação são instituídos como pontes de interface entre o Estado e a Sociedade. São funções do CME: acompanhar a execução dos planos educacionais, emitir pareceres técnicos sobre assuntos de natureza educacional e manifestar proposições sobre o aperfeiçoamento do sistema municipal de ensino. Uma vez que, as ações definidas no regime interno corroborem na promoção de políticas públicas educacionais com qualidade e equidade.

E devido a isso, para o CME ser mais eficiente, é dividido entre órgãos integrantes, bem como o Plenário, a Presidência, Câmaras, Comissões e Secretaria Executiva. Sendo composto por doze suplentes e doze titulares, tendo os mesmos o mandato de dois anos, prorrogável uma única vez e por igual período.

A competência crucial do Plenário é supervisionar o conselho na execução na forma da legislação vigente, assim como, elaborar políticas e diretrizes para o sistema municipal educacional. E já que, está interligado com o desenvolvimento dos mecanismos para melhorar a qualidade do ensino, é o plenário que realiza pesquisas sobre a situação da educação pública, e do município, além de ajustar ao melhor nível de produtividade. 
Sobre o papel do presidente do CME, cabe ao mesmo: dirigir, orientar e presidir. Assim sendo, é notória a presença de participar das reuniões, bem como convocar as extraordinárias e as ordinárias, além de, mobilizar os meios e recursos para o funcionamento, fazendo também o cumprimento das leis diante o Plenário e exercendo suas demais funções inerentes ao conselho. Sobre o nível de conhecimento dos conselheiros sobre os marcos legais e regimentais do CME:

Quadro 1. Conhecimento dos conselheiros em relação aos documentos referentes ao conselho do qual são membros.

\begin{tabular}{|c|c|c|c|}
\cline { 2 - 4 } \multicolumn{2}{c|}{} & \multicolumn{2}{c|}{ Nível de Conhecimentos \% } \\
\hline Documentos referentes ao conselho & Conhece bem* & Sabe que existe & Não conhece \\
\hline Lei Federal que regulamenta & $60 \%$ & $40 \%$ & $10 \%$ \\
\hline Lei Estadual que regulamenta & $50 \%$ & $40 \%$ & - \\
\hline Lei Municipal que regulamenta & $70 \%$ & $30 \%$ & $10 \%$ \\
\hline Estatuto e Regimento interno do CME & $90 \%$ & - & \\
\hline
\end{tabular}

* Já leu ou estudou o documento individualmente ou em grupo

\% Percentuais válidos excluindo os casos omissos (não respondeu, não sabe...)

Fonte: Autores.

O "braço direito" do presidente é a Secretaria Executiva, assessorando ele em assuntos de natureza técnica e administrativa. Ocorrendo de todas as atividades administrativas do Conselho competem à secretaria, bem como planejar, programar, organizar e coordenar as atividades do Conselho Municipal de Educação de Mossoró.

Todo conselho é disposto de Câmaras específicas que cada segmento expressa a melhoria da educação no município. Bem como, a de Legislação e Normas que compete a ela a proposições técnicas legais, e a elaboração de estudos de acordo com a adequação das decisões da legislação vigente, assim como a política educacional da cidade. Dispõe a Câmara de Planejamento, analisar e organizar o orçamento do conselho e elaborar o plano de ação do mesmo; diferentemente da Câmara de Educação infantil e Ensino fundamental, que aprecia as questões aos níveis de ensino e a adoção de sugestões e medidas para o aperfeiçoamento do mesmo.

O funcionamento do conselho depende também da sua estrutura, assim como é assegurado no artigo 31 do seu regimento interno. Instituindo que, o espaço irá funcionar em um centro administrativo, com toda estrutura necessária, tendo, salas de reuniões, cadeiras, birôs, computadores juntamente com impressoras, estantes, telefones e demais necessidades plausíveis. Além disto, os membros dos conselhos ficam encarregados de discutir os processos educacionais, sendo atribuídos a participar das discussões e deliberações do mesmo.

É bastante nítido, a formalidade e ao compromisso ao decorrer do documento, e em relação às sessões é ainda mais rígido. De acordo com o mesmo, o Conselho é obrigado a reunir-se em sessão plena ordinária ás 16 horas da primeira quinta feira de cada mês, sendo obrigado também em cada sessão a leitura da ata, o expediente, ordem do dia, e a informações, sendo tomadas as resoluções por maioria dos votos.

No tocante, ao desempenho dos conselheiros, buscou-se verificar quais comportamentos políticos têm caracterizado a presença dos representantes da sociedade civil e das instituições governamentais no CME. As variáveis analisadas foram: atitudes dos conselheiros (com base na qual construiu-se um índice de desempenho), e avaliação dos conselheiros sobre a efetividade e sobre os principais fatores que limitavam o funcionamento adequado da gestão participativa do mesmo. Vejamos a seguinte tabela: 
Quadro 2. Atitudes dos conselheiros quanto a atuação do CME.

\begin{tabular}{|c|c|c|c|c|}
\hline \multirow[b]{2}{*}{ ATITUDES } & \multicolumn{4}{|c|}{ FREQÜÛENCIA } \\
\hline & NUNCA & RARAMENTE & $\begin{array}{l}\text { ALGUMAS } \\
\text { VEZES }\end{array}$ & SEMPRE \\
\hline Ficar calado nas reuniões & $30 \%$ & $50 \%$ & $20 \%$ & - \\
\hline $\begin{array}{l}\text { Falar sempre concordando com os demais } \\
\text { conselheiros }\end{array}$ & - & - & $100 \%$ & - \\
\hline $\begin{array}{l}\text { Fazer críticas em relação ao tema ou questão em } \\
\text { debates }\end{array}$ & $10 \%$ & $10 \%$ & $70 \%$ & $10 \%$ \\
\hline $\begin{array}{l}\text { Expor aspectos da realidade nacional e local em } \\
\text { termos da educação, contribuindo nos debates }\end{array}$ & - & - & $30 \%$ & $70 \%$ \\
\hline $\begin{array}{l}\text { Apresentar propostas de } \\
\text { encaminhamentos }\end{array}$ & - & - & $60 \%$ & $40 \%$ \\
\hline Negociar propostas em discussão & - & $30 \%$ & $50 \%$ & $20 \%$ \\
\hline $\begin{array}{l}\text { Fazer cobranças sobre o cumprimento do que } \\
\text { foi definido }\end{array}$ & - & - & $70 \%$ & $30 \%$ \\
\hline $\begin{array}{l}\text { Assinar atas, relatórios, prestação de contas } \\
\text { mesmo quando não são realizadas as reuniões }\end{array}$ & $90 \%$ & - & - & $10 \%$ \\
\hline $\begin{array}{l}\text { Pedir ou solicitar } \\
\text { diretamente para a entidade ou setor que } \\
\text { representa }\end{array}$ & $70 \%$ & - & $10 \%$ & $20 \%$ \\
\hline
\end{tabular}

Fonte: Pesquisa realizada pelo autor (outubro de 2016).

a) As atitudes mais frequentes são: "expor aspectos da realidade, contribuindo nas discussões", "apresentar propostas de solução" e "cobrar o cumprimento das decisões do Conselho".

b) As atitudes menos frequentes são: "assinar documentos de modo ilegal” (sem haver apreciação do Conselho - relatórios e prestações de contas - e forjando atas) e a "solicitação de verbas e serviços para a entidade ou setor que representava diretamente" (atitude de pedinte). Essa última atitude citada adquire caráter negativo quando ocorre "sempre" tendo em vista que, no Conselho, podem estar sendo reproduzidas práticas de corporativismo que beneficiem apenas a entidade ou setor que está diretamente representando no conselho, revelando, também, a predominância da prática de reivindicação de interesses imediatos daqueles que estão presentes nos conselhos, podendo colocar em xeque a supremacia do interesse coletivo. Esta prática inviabiliza a proposta dos conselhos como espaços de ampliação da participação e controle social na gestão de políticas públicas.

c) Há um nível considerável de conselheiros respondentes que "às vezes" "ficam calados nas reuniões" ou "falam sempre concordando", totalizando $20 \%$ e 100\% respectivamente. Esse tipo de atitude tende a pender para a prática de cooptação do conselheiro, revelando a falta de preparação ou total desconhecimento para colocar em prática o seu papel e até podendo ser uma conformação com práticas tradicionais de gestão e de centralização do poder de decisão. Tendo em vista que as decisões a serem tomadas no espaço do conselho devem levar em conta as diferentes ideias e interesses, obtendo o consenso sobre quais encaminhamentos são melhores para a sociedade como um todo, promovendo o debate e as contradições de ideias fundamentais ao estabelecimento do consenso num processo decisório democrático.

Com base nessas informações coletadas foi possível construir um índice estatístico para medir o nível de desempenho dos respondentes quanto à participação no CME. Tomou-se por base critérios ou características (não convencionadas) de uma "participação ativa" e de uma "participação fraca", ou seja, meramente formal ou submissa no CME. 
Quadro 3. Construção de índices de desempenho.

\begin{tabular}{|l|l|l|l|l|l|l|l|l|}
\hline \multirow{2}{*}{ Atitudes } & \multicolumn{2}{|l|}{ Participação ativa } & \multicolumn{4}{l|}{ Participação fraca } \\
\cline { 2 - 11 } & Nível & $\begin{array}{l}\text { P } \\
*\end{array}$ & Nível & P & Nível & P & Nível & P \\
\hline Ficar calado & Nunca & 3 & Raramente & 2 & Ás Vezes & 1 & Sempre & 0 \\
\hline Falar concordando & Ás vezes & 3 & Raramente & 2 & Nunca & 1 & Sempre & 0 \\
\hline Fazer críticas & Às vezes & 3 & Sempre & 2 & Raramente & 1 & Nunca & 0 \\
\hline $\begin{array}{l}\text { Expor } \\
\text { conhecimento }\end{array}$ & Sempre & 3 & Às vezes & 2 & Raramente & 1 & Nunca & 0 \\
\hline $\begin{array}{l}\text { Apresentar } \\
\text { propostas }\end{array}$ & Sempre & 3 & Às vezes & 2 & Raramente & 1 & Nunca & 0 \\
\hline Negociar propostas & Ás vezes & 3 & Sempre & 2 & Raramente & 1 & Nunca & 0 \\
\hline Fazer cobranças & Sempre & 3 & Às vezes & 2 & Raramente & 1 & Nunca & 0 \\
\hline $\begin{array}{l}\text { Assinar } \\
\text { documentos } \\
\text { modo ilegal }\end{array}$ & Nunca & 3 & Raramente & 2 & Às vezes & 1 & Sempre & 0 \\
\hline Pedir recursos & Nunca & 3 & Raramente & 2 & Às vezes & 1 & Sempre & 0 \\
\hline Total de pesos & & & & & & & & \\
\hline
\end{tabular}

* $\mathrm{P}$ = peso atribuído a cada um dos níveis ou frequências das atitudes.

Fonte: Autores.

Para chegar ao índice médio de desempenho dos respondentes, foi utilizada a seguinte fórmula: $\sum \underline{(\mathrm{Fn} x \mathrm{Pn})}$

$\mathrm{N}$

Onde,

$\sum=$ somatório

Fn $=$ frequência de ocorrência de cada nível das atitudes

Pn = peso atribuído no Quadro 2 a cada nível de atitude

$\mathrm{N}=10$ (total de respondentes)

Logo,

Ficar calado: $\underline{3 \times 5+2 \times 0+1 \times 2+0 \times 1}=2,1$

10

E, assim seguindo as demais categorias para se estabelecer o índice médio de desempenho dos respondentes.

Tomando o nível de desempenho para cada um dos respondentes, verifica-se que há uma forte predominância do nível "excelente" e não ocorre nenhum caso de "baixo desempenho" vejamos o (Gráfico 4) que se segue: 


\section{Gráfico 1.}

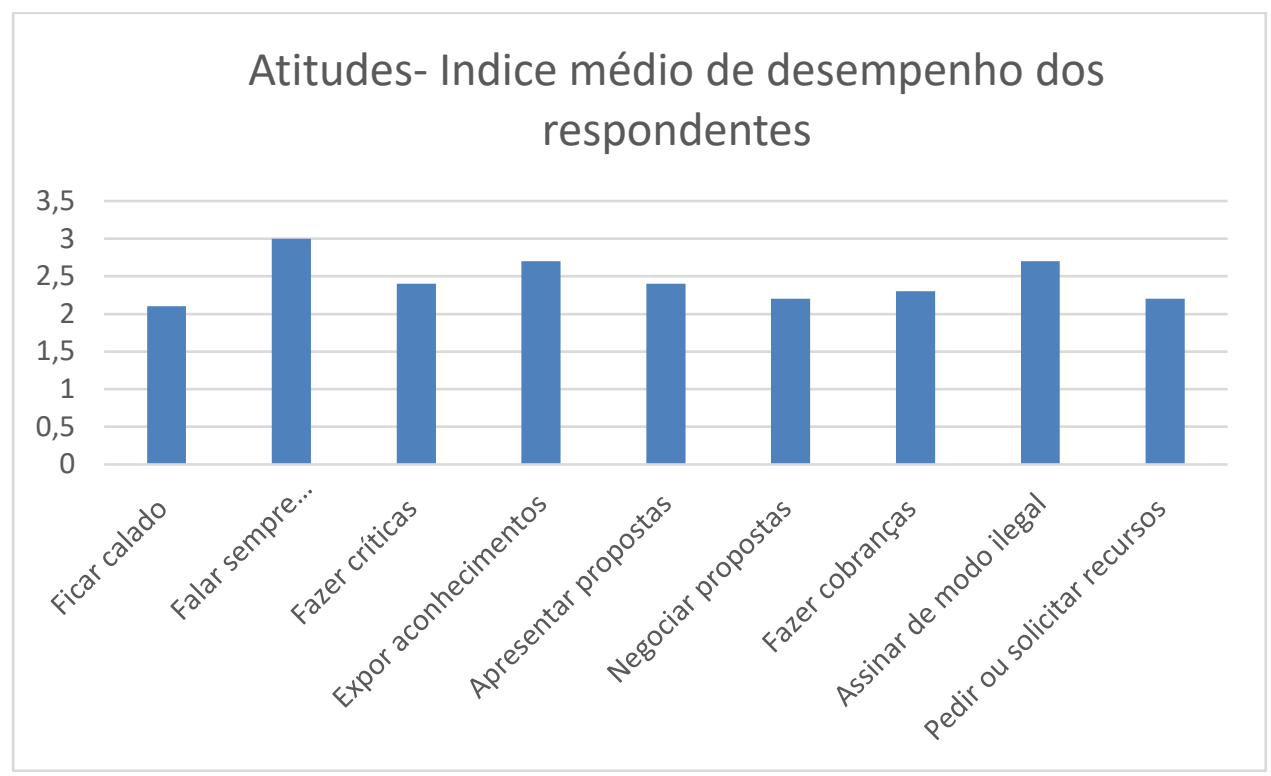

Fonte: Autores.

Tomando por base o índice construído pode-se considerar que o nível geral de desempenho dos conselheiros é “excelente" e "razoável” (ver Tabela 5) a seguir. Baseado em pesos atribuídos para cada um dos níveis das atitudes foi construída uma escala para medir o nível de desempenho dos respondentes, tendo como valores mínimo e máximo 0 e 30 pontos, respectivamente: de 0 a 8 pontos, baixo desempenho; de 9 a 16 pontos, desempenho insuficiente; de 17 a 24 pontos, desempenho razoável, e de 25 a 30 pontos, desempenho excelente.

Gráfico 2.

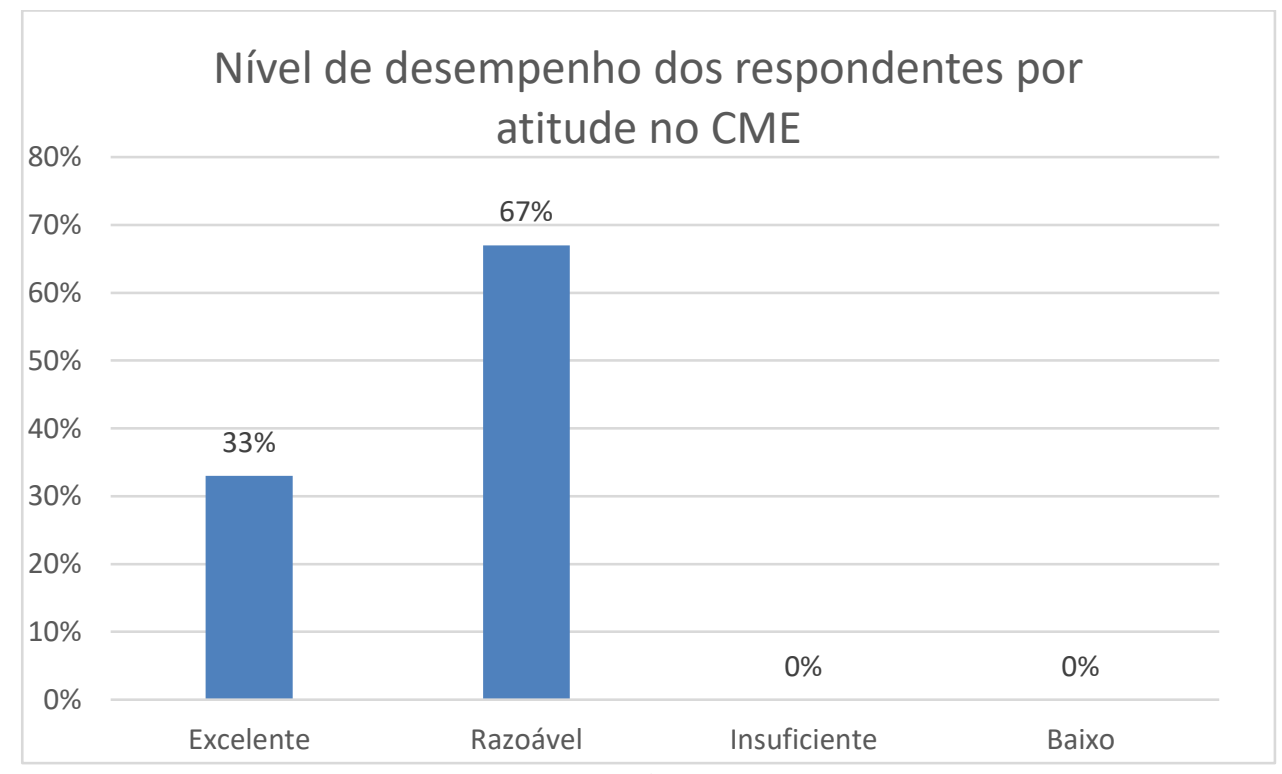

Fonte: Autores.

Em relação a disposições gerais e finais, foi verossímil levar em conta o artigo 49: "A participação no Conselho de Educação é considerada serviço público relevante, dispensado qualquer forma de remuneração".

E de fato é o que acontece, pois, ao realizarmos uma entrevista com um dos conselheiros, foi reafirmado que o trabalho é 
meramente voluntário onde os mesmos recebem ajudas de custo para as viagens e cursos para a representação do conselho. Podendose concluir que é uma força de trabalho admirável, já que, eles não recebem economicamente em troca, e apesar disso, utilizam seus tempos para melhorar e monitorar o sistema educacional da cidade de Mossoró. Sobre a atuação do CME na visão dos conselheiros:

Quadro 4. Avaliação dos conselheiros quanto à efetividade do CME.

\begin{tabular}{|c|c|c|c|c|c|c|}
\hline \multirow[b]{2}{*}{$\begin{array}{l}\text { Afirmações em relação aos conselhos } \\
\text { gestores }\end{array}$} & \multicolumn{6}{|c|}{ Grau de concordância \% } \\
\hline & Concorda & $\mathrm{P}$ & $\begin{array}{l}\text { Concorda } \\
\text { em parte }\end{array}$ & $\mathrm{P}$ & Discorda & $\mathrm{P}$ \\
\hline $\begin{array}{l}\text { Garante uma melhor qualidade das } \\
\text { decisões e relação à política setorial } \\
\text { no município }\end{array}$ & $62,5 \%$ & 3 & $37,5 \%$ & 1,5 & - & 0 \\
\hline $\begin{array}{l}\text { Garante maior legitimidade às } \\
\text { decisões tomadas nos município }\end{array}$ & $87,5 \%$ & 3 & $12,5 \%$ & 1,5 & - & 0 \\
\hline $\begin{array}{l}\text { Garante a execução e continuidade } \\
\text { das ações }\end{array}$ & $50 \%$ & 3 & $50 \%$ & 1,5 & - & 0 \\
\hline $\begin{array}{l}\text { Promove o engajamento solidário das } \\
\text { organizações na solução de } \\
\text { problemas }\end{array}$ & $75 \%$ & 3 & $25 \%$ & 1,5 & - & 0 \\
\hline $\begin{array}{l}\text { Diminui as práticas clientelistas e } \\
\text { patrimonialistas }\end{array}$ & $50 \%$ & 3 & $37,5 \%$ & 1,5 & $12,5 \%$ & 0 \\
\hline $\begin{array}{l}\text { Aumenta a lentidão dos processos } \\
\text { decisórios }\end{array}$ & $25 \%$ & 0 & $37,5 \%$ & 1,5 & $37,5 \%$ & 3 \\
\hline Reuniões não são produtivas & & 0 & $50 \%$ & 1,5 & $50 \%$ & 3 \\
\hline $\begin{array}{l}\text { Não toma decisões que sejam } \\
\text { efetivadas }\end{array}$ & $25 \%$ & 0 & $25 \%$ & 1,5 & $50 \%$ & 3 \\
\hline 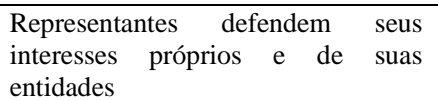 & $37,5 \%$ & 0 & $50 \%$ & 1,5 & $12,5 \%$ & 3 \\
\hline $\begin{array}{l}\text { A sociedade civil local não é } \\
\text { suficientemente representada no } \\
\text { conselho }\end{array}$ & $12,5 \%$ & 0 & $25 \%$ & 1,5 & $62,5 \%$ & 3 \\
\hline $\begin{array}{l}\text { Decisões são totalmente dependentes } \\
\text { da vontade do executivo municipal }\end{array}$ & - & 0 & $37,5 \%$ & 1,5 & $62,5 \%$ & 3 \\
\hline $\begin{array}{l}\text { Não dispõe dos meios e recursos } \\
\text { necessários para realizar sua missão }\end{array}$ & $37,5 \%$ & 0 & $25 \%$ & 1,5 & $37,5 \%$ & 3 \\
\hline $\begin{array}{l}\text { Contribui para a efetividade das } \\
\text { políticas públicas educacionais do } \\
\text { Município. }\end{array}$ & $60 \%$ & 3 & $30 \%$ & 1,5 & $10 \%$ & 0 \\
\hline
\end{tabular}

\% Percentuais válidos excluindo os casos omissos (não respondeu, não sabe...)

Foram atribuídos pesos $(3-1,5-0)$ aos graus de concordância às questões de acordo com a efetividade do CME

Fonte: Pesquisa realizada pelo autor (outubro de 2016).

Os dados resultantes dos questionários fechados confirmaram que em termos de efetividade, ou seja, diante da dinâmica interna do CME e suas atribuições, as ações desenvolvidas nas percepções dos conselheiros estabeleceram um significativo desempenho em conformidade com os objetivos normativos, quando propõem que os conselhos gestores de políticas públicas possam se constituir em espaços de participação, de discussão dos problemas e demandas locais da educação por exemplo, e de legitimação das decisões tomadas no município. Sobre essa avaliação os resultados são os seguintes: $62,5 \%$ dos conselheiros respondentes dizem que o conselho teve um bom desempenho na gestão participativa e 37,5\% dos entrevistados confirmam que foi razoável. Além disso, $60 \%$ dos conselheiros respondentes, concordam plenamente e $30 \%$ concordam em parte sobre a contribuição do CME na efetividade das políticas educacionais do município. Sobre a avaliação da efetividade do CME, vejamos o (Gráfico 3): 
Gráfico 3.

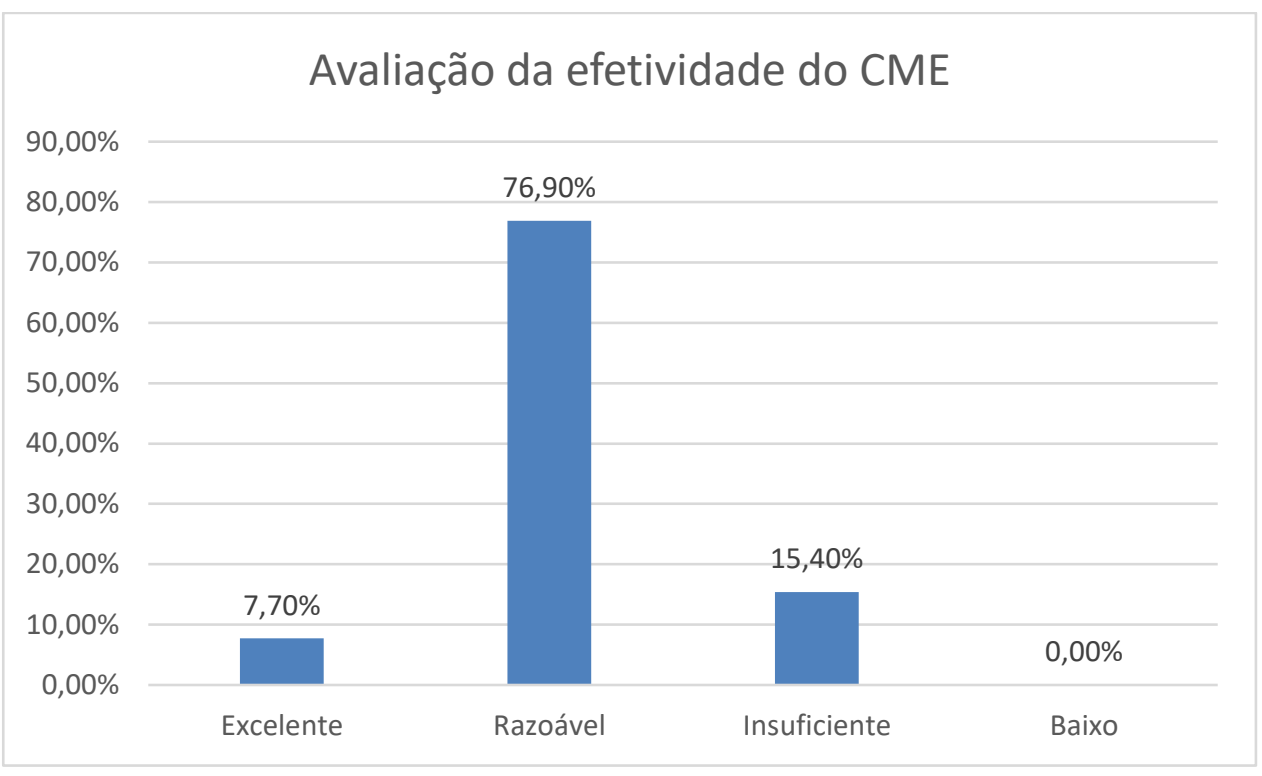

Fonte: Autores.

Ao confrontar os resultados do questionário eletrônico formulado no Google Forms, com a análise qualitativa por meio das entrevistas realizadas com quatro conselheiros, sendo dois da representação da administração municipal e dois da sociedade civil, constata-se algumas divergências no que diz respeito à prática cotidiana da gestão participativa, por exemplo, quando indagados sobre os diferenciais do CME como arranjo político participativo no acompanhamento das políticas públicas educacionais do município, um dos entrevistados relata:

Esses arranjos, as pessoas que estão no Conselho, digo a "cabeça" do Conselho, o Presidente, e ainda existem pessoas que eram para ter saído, e eu vejo muito a questão política muito presente, que impede que o Conselho cumpra o seu papel. Porque, primeiro, o Conselho tem que ser apolítico, ele não tem que ser partidário, ele tem que olhar para todos os segmentos e respeitar a sua opinião. Algo que eu percebi é que muitas vezes quando alguém que está questionando ali dentro, não é valorizado, então com relação à contribuição do Conselho, há contribuição do Conselho, pois há um Conselho que vai nos dar um suporte, que pode vim melhorar a nossa educação de forma local, mas ainda as pessoas que estão lá ainda não tem essa visão, é como se o Conselho lhe pertencesse, é como se o Conselho fosse seu, ainda há um autoritarismo muito grande, é tanto que as vezes eu vou e me questiono que estou no canto errado, pois a fala dos outros que choca com a da Presidente, que ela não é democrática e sim autocrática, causa esse mal estar. Então eu acredito que quando as pessoas tiverem uma visão ampla do que seja o Conselho, da importância que seja o Conselho, aí sim teremos uma política educacional forte, teremos escolas com mais autonomia, e pelo contrário, coisas que tínhamos que está dentro da LDB (Lei de Diretrizes Bases da Educação Nacional), o conselho municipal de educação nos tirou, como calendário escolar, que era organizado de acordo com a realidade escolar, quer dizer que muitas coisas que tínhamos direitos, foram negados por eles. Uma coisa, eu acredito, o Conselho em si é bom, mas da forma que está funcionando hoje, eu não acredito. Eu fico triste que faço parte dele, tento dar minha contribuição, mas infelizmente ainda ele é regido por um grupo que acha que ser autoritário, de centralizar as coisas, não deixar que o outro participe, isso impede o crescimento do Conselho. (Entrevistado (a) 1. Entrevista concedida em 17 de novembro de 2016).

Observa-se no relato supracitado que a atuação do CME precisa avançar nos critérios de igualdade e inclusividade, de modo a assegurar a igualdade de participação de todos os membros e para que os mesmos se sintam pertencentes ao processo decisório. Considerando a participação do CME na efetividade das políticas públicas educacionais do município de Mossoró-RN, destaca o (a) entrevistado (a) 01:

Não, complementa a pergunta da outra. Me mostre o que foi feito no antes e depois? O que seria uma coisa que venha complementar ou melhorar? A Escola Municipal Professor Manoel Assis tem o segundo melhor IDEB (Índice de 
Desenvolvimento da Educação Básica), eu vou dizer que teve a participação? Não! Para se ter uma ideia eu gosto muito de parabenizar o professor pelo seu trabalho, nós temos que valorizar o servidor, nesse caso o professor. Nós somos o segundo melhor do Estado e o Conselho sequer manda uma carta para parabenizar. Eles têm participação nisso? Não! Quais são as ações? Conferências se as horas aulas dos alunos estão sendo cumpridos. Mandei uma solicitação para o Conselho sobre o meu arquivo passivo, das caixas de lá de 67, até agora ninguém me respondeu. Não existe troca de informações. É um grupo que se formou, mas que na verdade não tem um objetivo. Não vejo como ser um Conselho que agregou melhorias à educação, e sim um órgão que na questão do MEC como aquela cidade que tem um Conselho Municipal de Educação, mas em trazer para as escolas não sentimos nada, continua na mesma inércia, sem nada, o que nós fazemos é com recursos nossos, é com conhecimentos nosso, formação nossa. O Conselho é a mesma coisa de não existir. (Entrevistado (a) 1. Entrevista concedida em 17 de novembro de 2016).

Com o intuito de se firmar como instância de gestão participativa o CME necessita otimizar o compartilhamento de informações entre os conselheiros e suas câmaras técnicas e, acima de tudo publicizar as suas ações, fortalecendo os seus atores como sujeitos políticos autônomos em prol de garantir resultados que vão ao encontro das necessidades da sociedade local, otimizando o uso dos recursos e esforços da rede, na medida que consolida a transparência da sua gestão e os laços com a sociedade local.

O Conselho Municipal de Educação de Mossoró está instituído como um canal paritário, pela divisão de números de pessoas iguais de conselheiros, tanto com elementos de seis conselheiros da sociedade civil e seis para administração pública, buscando cada grupo um consenso para de modo geral, ajustar ainda mais a situação educacional.

A função consultiva é ter um caráter de assessoramento, verificando as questões conduzidas pelos diversos segmentos do CME e apresentando soluções, que poderão ou não ser implementadas. De acordo com a pesquisa foi perceptível notar que o conselho é consultivo, devido a secretaria de hoje ter sido uma conselheira passada, tendo tipo uma boa participação atualmente, pelo fato de que a mesma já foi uma conselheira que além de conhecer, respeita as opiniões trazidas pelo conselho.

Apesar do Conselho Municipal de Mossoró não cooperar da forma em que poderia contribuir, por ter uma dificuldade de estrutura, falta de transporte nem sempre a disposição dos conselheiros e os próprios tendo que realizar tarefas por conta própria, dificulta bastante para o aprimoramento das políticas públicas educacionais. Tendo a deliberação conceituada de como o conselho aprova, conduz e acompanha conflitos, propõe a criação e produção de normas internas e o cumprimento das normas dos sistemas de ensino e decide sobre a organização e o funcionamento geral da escola, apresentando junto à direção as ações a serem desenvolvidas.

O conselho de Mossoró nos traz a deliberação na forma em que os conselheiros conhecem e deliberaram sobre o processo e resultados da avaliação externa e interna do funcionamento da escola, propondo planos que visem à melhoria do ensino, desenvolvimento estratégico das escolas, entre outros aspectos que conseguimos observar indo ao Conselho, estando junto e analisando a forma que os conselheiros interagem em cada situação de escolhas como essas, para a melhoria, a identificação de problemas e funcionamento das escolas. Em que, de acordo com Jacobi \& Pinho (2006, p. 110):

Os processos deliberativos ou as possibilidades de composições deliberativas, quer promovidos pelo poder público ou pelos diferentes enclaves da sociedade civil, sugerem uma sociedade apta a atuar democraticamente. O significado dessa capacidade de ação democrática não passa somente pelo momento do voto, pelo momento da decisão da maioria. Nas sociedades democraticamente deliberativas todos, de modo organizado ou não, institucional ou informalmente, têm direito a expor suas razões, a argumentarem e negociarem suas inquietações e soluções. No processo deliberativo de decisão está implícita a dialogicidade das relações sociais, de uma deliberação comunicativa na qual a isonomia é o modus operandi na incorporação negociada das individualidades.

A atuação do CME como instância de deliberação permite um maior controle social das decisões tomadas, bem como das políticas educacionais implementadas, a deliberação tem uma forte ligação com o processo de implementação e execução das políticas públicas educacionais a priori discutidas e decididas. 
A avaliação prescritiva da atuação do Conselho Municipal de Educação de CME de Mossoró-RN considera a dinâmica da democratização e da descentralização do processo decisório sobre as políticas públicas educacionais implementadas no município como pontos focais para o êxito das políticas frente as demandas prioritárias da agenda pública educacional local. A democratização e a descentralização da gestão pública no Brasil são processos ancoras para um maior controle social das ações em todo o ciclo de vida das políticas públicas.

Dessa forma, ao diagnosticar e avaliar a atuação do CME de Mossoró-RN através da sua proposta de gestão participativa. A avalição prescritiva possibilita mapear as percepções dos atores relevantes sobre o processo decisório, bem como, sobre a caracterização dos problemas/demandas da agenda pública educacional local, a elaboração das políticas, sua implementação e os principais resultados.

A avaliação prescritiva aqui desenvolvida, possibilitou estudos sobre os fatores políticos e institucionais do Conselho em sua trajetória histórica de 21 anos de constituição, e, em específico, as gestões no período de análise de 2016 a 2018 . Este tipo de avaliação possibilita também apontar alternativas de melhoria e superação aos gargalos da gestão das políticas em curso no período examinado.

A gestão estratégica deve considerar os conselhos gestores de políticas educacionais como instâncias de formulação, implementação, acompanhamento e avaliação dos resultados/impactos das políticas, adotando um foco de longo prazo, de articulação de diversos atores e projetos, revisando processos e garantindo publicidade, transparência e responsabilidade diante das ações executadas.

A matriz de SWOT é uma ferramenta de diagnóstico, possibilitando mapear riscos e mudanças do ambiente externo de uma organização/instituição, verificando também as tendências políticas, culturais, legais e administrativas, podendo ajudá-la a conquistar oportunidades e a lidar com as ameaças exógenas. No tocante, ao ambiente interno, possibilita verificar forças que diferenciam e são propulsoras de superação das limitações da proposta gestão participativa do CME nos municípios. Nas fraquezas são verificadas as características que atrapalham a atuação do conselho como espaço de participação e controle social para a efetividade das políticas educacionais.

A aplicação da matriz SWOT permitiu um diagnóstico situacional do Conselho Municipal de Educação e o seu papel na efetividade das políticas educacionais municipais. Segundo Tavares (2010) a análise SWOT, também conhecida como FOFA (em sua tradução) é uma técnica que faz a relação entre o ambiente interno e externo da organização, verificando alguns fatores que limitam ou otimizam o desempenho da organização.

Através das entrevistas realizadas com quatro conselheiros e do questionário online com 10 conselheiros respondentes, foi possível a identificação dos fatores externos e internos que influenciam o Conselho Municipal de Educação nas realizações de suas funções. No Quadro 5, detalhamos todos os aspectos identificados como oportunidades, ameaças, forças e fraquezas relacionados aos dados coletados. 
Quadro 5. Matriz SWOT do Conselho Municipal de Educação.

\begin{tabular}{|c|c|c|}
\hline \multirow[b]{2}{*}{ 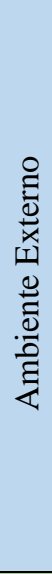 } & Oportunidades & Ameaças \\
\hline & $\begin{array}{l}\text { Melhorias na educação; } \\
\text { Elevação da renda per capita brasileira; } \\
\text { Estado mais forte e atuante; } \\
\text { Elaboração de seus respectivos planos municipais } \\
\text { de educação; } \\
\text { Melhorias das políticas educacionais; } \\
\text { Fazer um elo entre a sociedade e a administração } \\
\text { pública; } \\
\text { Maior participação social; } \\
\text { Políticas públicas eficazes, eficientes e efetivas; } \\
\text { Elevação do IDEB (Índice de Desenvolvimento da } \\
\text { Educação Básica); }\end{array}$ & $\begin{array}{l}\text { Mudança de governo; } \\
\text { Mudanças na legislação brasileira; } \\
\text { Estado mais fraco e menos atuante; } \\
\text { Falta de fiscalização dos órgãos competentes; } \\
\text { Falta de fiscalização da sociedade; } \\
\text { Vínculos com partidos; } \\
\text { Menor participação social; } \\
\text { Políticas públicas ineficazes, ineficientes e sem } \\
\text { efetividade; } \\
\text { Falta de recursos necessários; }\end{array}$ \\
\hline \multirow[b]{2}{*}{ 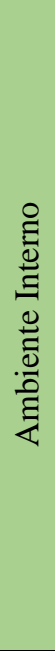 } & Forças & \\
\hline & $\begin{array}{l}\text { Membros capacitados; } \\
\text { Participação da sociedade civil na atuação do } \\
\text { conselho; } \\
\text { Bom ambiente de trabalho; } \\
\text { Programa Nacional de Capacitação de } \\
\text { Conselheiros Municipais de Educação; } \\
\text { Paridade entre a administração pública e a } \\
\text { sociedade civil } \\
\text { Órgão fundamental para o desenvolvimento da } \\
\text { educação no âmbito Municipal } \\
\text { O Conselho é um canal para obter maior } \\
\text { conhecimento legislativo federal, estadual e } \\
\text { municipal }\end{array}$ & $\begin{array}{l}\text { Falta de comunicação entre os membros do } \\
\text { Conselho; } \\
\text { Falta de tempo dos conselheiros para se dedicar ao } \\
\text { Conselho; } \\
\text { Pouca atuação do conselho no enfrentamento de } \\
\text { problemas educacionais } \\
\text { Propostas que não são executadas; } \\
\text { A população não tem poder de decisão no } \\
\text { Conselho } \\
\text { As reuniões deveriam ser melhor divulgadas e } \\
\text { realizadas em espaço amplo } \\
\text { Dependência do Poder Executivo Municipal }\end{array}$ \\
\hline
\end{tabular}

Fonte: Elaborado pelo autor (outubro de 2016).

Desse modo, faz-se importante destacar a título de proposições estratégicas que a atuação do Conselho Municipal de Educação deverá considerar uma abordagem sistêmica, ou seja, integral e articulada do conjunto dos fatores organizacionais e as suas múltiplas influências, com o intuito de obter informações que reorientem a gestão para novos patamares organizacionais e efetividade das políticas públicas educacionais.

Sobre a relevância da gestão estratégica das políticas públicas para a obtenção de informações para a condução do processo decisório mais assertivo, assinalam Dias e Matos (2012, p.133):

[...] ajuda a administração a se adaptar às condições mutáveis do ambiente e a solidificar os acordos considerando os aspectos principais; possibilita a definição de responsabilidades com mais precisão; dá mais ordem às operações; contribui para melhorar a coordenação das diversas partes da organização; tende a tornar os objetivos mais específicos e mais conhecidos, diminui as conjecturas e especulações, economiza tempo e esforço, dinheiro, e principalmente, ajuda a diminuir erros nos momentos de tomada de decisão

A análise prescritiva do CME tem como finalidade garantir funções informativa, criativa, argumentativa e legitimadora que combinaram num repertório de informações para a superação das limitações institucionais, culturais e organizacionais, na medida em que haja uma reorientação na gestão participativa com base nos parâmetros da eficácia, eficiência, relevância, efetividade, sustentabilidade e equidade de políticas públicas. Sobre as funções da análise prescritiva, destaca Secchi (2016, p.1617): 
Função informativa: diagnosticar um problema público, seu contexto, suas causas e consequências; prover informações úteis ao processo decisório; aconselhar o tomador de decisão a escolher a alternativa mais adequada.

Função criativa: desconstruir entendimentos consolidados sobre problemas públicos e gerar alternativas de política pública utilizando criatividade estruturada;

Função argumentativa: fornece e evidenciar argumentos para o embate político, mediar e dissolver conflitos políticos com processos argumentativos quanto a decisões políticas a serem tomadas.

Função legitimadora: gerar aceitação entre os atores sobre política pública já formuladas; legitimar alternativas de política pública que ainda serão implementadas.

A gestão estratégica tem a função sistêmica de lidar com os desafios organizacionais, considerando fatores internos e externos que influenciam na formulação, implementação e avaliação dos resultados da política pública. A análise de SWOT permite a investigação das forças e fraquezas do ambiente interno e das oportunidades e ameaças do ambiente externo e envolvente. Focar nessas dimensões possibilita um maior controle no conjunto das ações do CME e suas contribuições para a efetividade das políticas públicas educacionais municipais.

\section{Considerações Finais}

O foco da gestão participativa do CME de Mossoró-RN consiste em promover um espaço de diálogo e cooperação com desempenho democrático e conectividade, estimulando o planejamento estratégico das políticas públicas educacionais em resposta às demandas locais. A pesquisa aqui apresentada atingiu o objetivo de avaliar e fazer prescrições acerca da atuação do CME de Mossoró-RN.

Desse modo, a pesquisa evidencia conforme as percepções dos stakeholders que o CME se constitui como espaço paritário e articulador dos atores sociais relevantes, consultivo com contribuições no ciclo de vida das políticas educacionais conforme as suas competências legais e regimentais.

Com o intuito de proposições e melhorias da atuação do CME de Mossoró-RN é recomendável a ampliação das formas de comunicação e compartilhamento de informações entre os membros internos e, com as demais instâncias do poder público local e a sociedade, ampliando o acesso as informações diante do histórico de suas ações e possibilitando a responsabilidade compartilhada.

Ainda de acordo com o estudo sobre a atuação do CME é necessário cultivar um ambiente de confiança e transparência que assegure aos conselheiros a certeza do desempenho efetivo dos seus papéis e o devido reconhecimento de suas contribuições, dando continuidade as decisões e deliberações previamente tomadas. Qualificando mais ainda os processos já existentes em sua dinâmica cotidiana e processo decisório.

A atuação do CME deve ser pautada na descentralização do processo decisório e no reconhecimento do conselho como instância de controle social das políticas públicas pela sociedade local. Para isso, o conselho tem que se efetivar como instância paritária, consultiva, deliberativa e, sobretudo, garantidora da supremacia do interesse coletivo na execução das ações educacionais. É perceptível nesse momento que a gestão participativa de políticas públicas é um conjunto de decisões interrelacionadas, concernindo a seleção de objetivos razoáveis e mensuráveis diante dos problemas públicos, dos meios para alcançar os objetivos dentro de uma situação específica e o impacto desejado, ou seja, de transformação social e, portanto, de resolutividade das demandas educacionais no município pesquisado, primando pela qualidade e equidade das políticas públicas educacionais. Desse modo, como sugestão de pesquisa futura, no contexto da e pós pandemia, a pesquisa aplicada acerca do uso de tecnologias de inteligência coletiva e formação de redes para a deliberação nos ciclos de gestão de políticas públicas.

\section{Referências}

Acselrad, H., \& Leroy, J-P. (1999). Novas premissas da sustentabilidade democrática. Cadernos de debate Brasil Sustentável e Democrático, n. 1. FASE, p. 11-47. 
Bardin, L. (1977). Análise de conteúdo. Edições 70.

Brasil, Governos Federal. (2004). Constituição Federal 1988. Governo Federal.

Brasil, Lei Darcy Ribeiro (1996). (2006). Lei de Diretrizes e Bases da Educação. (3a ed.), Senado Federal, Subsecretaria de Edições Técnicas, $177 \mathrm{p}$.

Brasil, Plano Nacional de Educação - PNE. (2014). Plano Nacional de Educação 2014-2024: Lei 13.005, de 25 de junho de 2014, que aprova o Plano Nacional de Educação (PNE) e dá outras providências. Brasília: Câmara dos Deputados, Edições Câmaras, 86p.

Batista, Neusa Chaves. (2009). A formação dos conselhos municipais de educação e a gestão democrática dos sistemas municipais de ensino: uma política pública em ação. 2009, 250 p. (Tese de Doutorado em Educação) - do Programa de Pós-Graduação em Educação, da Universidade Federal do Rio Grande do Sul - UFRGS.

Cohen, E. \& Franco, R. (1993). Avaliação de projetos sociais. Vozes, 312p.

Dagnino, E. (2002). Sociedade civil, espaços públicos e a construção democrática no Brasil: limites e possibilidades. In: Dagnino, E. Sociedade civil e espaços públicos no Brasil. Paz e Terra, p. 279- 301.

Dias, Reinaldo \& Matos, Fernanda. (2012). Políticas Públicas: princípios, propósitos e processos. Atlas.

Galdino, A. G. (2017). Participação social no desenvolvimento de políticas públicas no Estado do Amapá: um olhar sobre a elaboração e execução do Plano Plurianual de Macapá-AP no período de 2013 a 2016. Fortaleza-CE: Tese do Programa de PósGraduação em Sociologia da UFC, 305p.

Godoy, A. S. (1995). Introdução a pesquisa qualitativa e suas possibilidades. Revista de Administração de Empresas, 35, 57-63

Gohn, M. da G. (2001). Conselhos gestores e participação sócio-política. São Paulo: Cortez. (Coleção questões da nossa época, 84,120 p.

Jacobi, P., \& Pinho, J. A. (2006). Inovação no campo da gestão pública local: novos desafios, novos patamares. Editora FGV.

Libâneo, J. C. (2013). Organização e Gestão da Escola: Teoria e Prática. (6a ed.), Heccus Editora.

Lima, P. G., et al (2018). Conselhos municipais de educação: participação, qualidade e gestão democrática como objeto de recorrência. Rev. Diálogo Educ., 18, 326-347

Kleba, M. E., Carmelatto, D., \& Frozza, K. M. (2015). Instrumentos e Mecanismos de Gestão: contribuições ao processo decisório em conselhos de políticas públicas. Rev. Adm. Pública 49(4):1059-1079

Kotler, P., \& Keller, K. L. (2016). Administração de Marketing. (12a ed.), Pearson Prentice Hall.

Marconi, M. de A., \& Lakatos, E. M. (2008). Fundamentos de Metodologia Científica. (6a ed.), Atlas.

Martins, H. F.. (2003). Uma teoria da fragmentação de políticas públicas: desenvolvimento e aplicação na análise de três casos de políticas de gestão pública. Tese do Programa de Pós-Graduação em Administração da Escola Nacional de Administração Pública e de Empresas da FGV, 254p.

Moura, A. S. de. (2010). Democracia, participação e controle social nos Conselhos Municipais de Educação. João Pessoa - PB. $166 \mathrm{p}$.

Oliveira, M. M. de. (2007). Como fazer pesquisa qualitativa. Vozes.

Rico, E. M., et. al. (2007). Avaliação de políticas sociais: uma questão em debate. (5a ed.), Cortez: Instituto de Estudos Especiais, $155 \mathrm{p}$.

Rosa, M. V. de F. P. do C., \& Arnoldi, M. A. G. C. (2008). A entrevista na pesquisa qualitativa: mecanismos para validação. Autêntica.

Secchi, L. (2016) Análise de políticas públicas: diagnóstico de problemas, recomendação de soluções. Cengage Leaning. 
Soares, J. A. \& Bava-caccia, S. (1998). Os desafios da gestão municipal democrática. Cortez.

Santos, S. R., Azevedo, M. A. \& Marcelino, F. T. (2017). Avaliação participativa das políticas como proposta inovadora no setor público: delineamentos e procedimentos. Revista Eletrônica Científica Ensino Interdisciplinar - RECEI. 3.

Tavares, E. M. F. (2011). Gestão Participativa e políticas públicas: uma avaliação do PRONAF. Mossoró,RN: Sarau das Letras, $172 \mathrm{p}$.

Tavares, E M F. (2017). Percepções dos stakeholders acerca da gestão participativa do CMDR de Serra do Mel -RN, Revista Contribuciones a las Ciencias Sociales, (enero-marzo 2017). http://www.eumed.net/rev/cccss/2017/01/cmdr.html http://hdl.handle.net/20.500.11763/cccss1701cmdr

Tavares, M. C. (2010). Gestão Estratégica. (3a ed.), Atlas.

Texeira, E. C. (2001). O local e o global: limites e desafios da participação cidadã. (2a ed.), Cortez, EQUIP; UFBA, 224p.

Valle, V. R. L. do.(2011). Direito fundamental à boa administração e governança. Fórum, 193p. 